\title{
Tourism Development Model Analysis of Wutai Tribe of Rukai in Taiwan
}

\author{
Hsiao-Ming Chang ${ }^{1}$, Cheng-Lung $\mathrm{Wu}^{2 *}$ \\ ${ }^{1}$ School of Physical Education \\ Putian University, China \\ ${ }^{2}$ Department of Marine Sports and Recreation \\ National Penghu University, Taiwan \\ *Corresponding author's email: jerrywu [AT] gms.npu.edu.tw
}

\begin{abstract}
This study applied qualitative research to explore the model of tribal tourism industrial development of Wutai Township in Pingtung. According to the analytical results, the main attractions of tribal tourism are indigenous peoples' culture, natural resources, and convenient transportation. This study also included the promotion and tourism information of governmental sectors and tribal organizations, as well as hospitality services offered by the tribes. The key of tribal tourism is the cooperation of the indigenous peoples, and their tolerance and respect for the visitors.
\end{abstract}

Keywords--- tribal touris m, indigenous people, community construction

\subsection{Research motivation and purpose}

\section{INTRODUCTION}

In recent years, the diverse operations of indigenous tribes have successively become a trend, and have provided new economic opportunities for the tribes. The transformation of traditional indigenous tribe industries combine the characteristics of local res ources and the development model of touris m. Indigenous tribes are mostly in remote areas (or mountains), and they allow people from cities to approach nature and experience the cultures of different ethnic groups, thus, they have become potential tourismproducts of Taiwan. As tourists travel to Indigenous areas or tribes, they want to see their historical buildings, culture, handicrafts and traditional celebrations. However, with regard to the tourism development policy of the Taiwan government, not every tribe is suitable for tourism development, and even become a popular tourist attraction [1,2]. At present, touris mdevelopment in the Wutai tribe has been recognized by the government of Taiwan as the model of indigenous tribal tourismin the country. The local government has been devoted to the planning and development of guesthouse tourism, and created the "slate town". In 2001, it constructed Slate Lane, which shows the primitive and indigenous culture of the Wutai tribe, as well as numerous indigenous tribeimages with artistic characteristics $[3,4]$. Thus, as tourists crowded into the area after the construction of Slate Lane, numerous indigenous tribes in Taiwan regard the village as a model [5]. Based on above, this study adopts case research, literature review, field interviews, and long-termobservations, analyzes the tourism development process of the Wutai tribe, and takes the operational model to serve as reference for the tourismdevelopment of other indigenous tribes.

\subsection{Research method}

This study adopts the qualitative research method to conduct the investigation. Firstly, in the literature analysis part, it mainly collects reports and introductions about Wutai tribe, included the Internet, newspapers and mag azines, mas s media, books, research papers, and government research reports. Secondly, in the in -depth interview part, we mainly interviewed the elders, residents, handicrafts sellers and the Development Association personnel of the tribe. Thirdly, in the observation part, the researcher used the holiday to travel and stay in the tribe for many times, during which the interaction between indigenous people and tourists was observed in depth. In addition, the study also interviewed tourists, so as to better understand the development of tourismand their understanding and satisfaction of indigenous culture.

\section{INTRODUCTION OF WUTAI TOWNSHIP OF PINGTUNG COUNTY}

According to the announcement of the Taiwan Council of Indigenous Peoples, in 2019, there were 571,427 indigenous people in Taiwan [6]. At present, there are 16 ethnic groups of indigenous peoples, including Amis, Atayal, Paiwan, Bunun, Puyuma, Rukai, Tsou, Saisiat, Yami, Thao, Kavalan, Taroko, Sakizaya, Seediq, Hla'alua, and Kanakanavu, which arebased on individual cultures, languages, customs, and social structures. Rukai can be divided into three groups: the Xia San community in the Maolin Dis trict of Kaohsiung, Wutai Township of Pingtung County, the original Rukai group in Qingye 
Village of Sandimen Township, and the Danan group in Tungxing New Village, Beinan Township, Taitung County. Since the original Rukai group is located in remote mountains, according to scholars, it preserves the most Rukai features [7]. Among indigenous peoples in Taiwan, the most significant cultural characteristic of Rukai is its hierarchy system, where the family of the chief is the greatest landowner and leader of the tribe. Nevertheless, with the progress of time, social development, and national influence, Christianity and Catholicism have been introduced in the tribal society, and the traditional tribal lifestyle is dramatically changed. In addition, with the constant changes of society, the values of the traditional hierarchy system are twisted and even neglected [8]. The Totem of Cottonmouth is a feature of Rukai, and represents the s on-in-law and family of the Rukai chief (see Figure 1). The Totemof Cottonmouth denotes the identity as a noble and one of the family members of the chief. Regarding culture and ceremonies, the lily is one of the most significant characteristics of Rukai (s ee Figure 2).

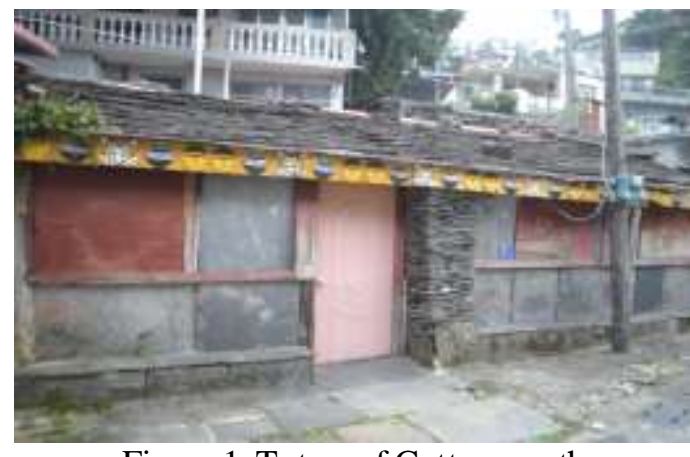

Figure 1. Totemof Cottonmouth

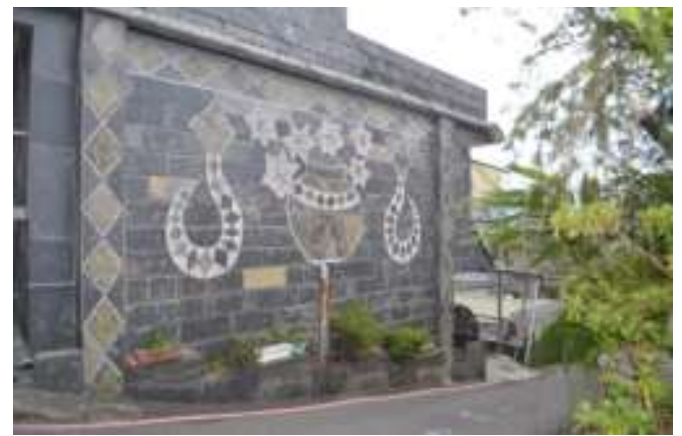

Figure 2. Totems of Cottonmouth and lily

Around Taiwan, there are more than 13000 Rukai people, who are mostly in Kaohsiung City, Pingtung County, and Taitung County, and Wutai Township of Pingtung County is the main town of Rukai people. Wutai Township includes Wutai Village, Dawu Village, Jilu Village, Ali Village, Haocha Village, and Chiamu Village. The Wutai tribe is the administration center of Wutai Township and the largest Rukai Village, and further includes the Wutai tribe, Shenshan tribe, and Kuchuan (Yila) tribe. Although the Wutai tribe is not the most ancient tribe, it is the center of politics and culture. There are numerous people in the tribe who mostly follow the Christian faith (Presbyterian Church, the Sabbath Day and Catholicis m), and the scale of the churches is the largest, thus, it relatively guides and influences other Rukai tribes. Since Wutai Township is located in a remote area and far from the cities, entrance requires a Class A entry permit and transportation is inconvenient, thus, the invasion of the Han culture from the lowland was late. At the end of 1973, the government was devoted to the improvement of tribal life, and constructed external transportation lines to allow vehicles to arrive in Wutaitribe.

\section{DEVELOPMENT OF THE TOURISM INDUSTRY OF WUTAI TRIBE}

In 1987, Taiwan's government selected six indigenous tribes to implement a "guesthouse village project", and Wutai tribe was one of those selected. However, this pioneer development was introduced from other countries, such as Japan, and the residents were not familiar with the hos pitality required by guesthouses. In addition, as the local infras tructure was not complete, local residents mostly treated the guesthouse project as a subsidy to improve local living environments, and reconstruct houses, kitchens, and s anitary facilities. Since1990, when may or Chi-Chuan Ko assumed office, he has actively planned and developed tourism in the area. Based on the experience of foreign guesthouse implementation, in 1994, he introduced the guesthouse village project and invited a Japanese professor to give a speech in Wutai to share the experiences of guesthouse hospitality and operation, in order to guide local residents to manage guesthouses. Thus, local res idents' operational concepts of guesthouses were derived from the hospitality of Japanese guesthouses. In 1995, the "Ancestral arch" was constructed, which is the entrance image of Wutai Township, thus, when visitors enter Wutai Township, they could recognize the exotic climate. As local modern building could not represent the original characteris tics of the tribe, starting in 1999, the government subsidized refurbishing the walls of the houses (with slate), slate roofs, slate totem, etc. Thus, year by year, the "slate village" of the Wutai tribe was recovered.

In 1997, the Executive Yuan of Taiwan initiated "theproject of new landscapes for cities and towns", and numerous old streets and important tourist sites in Taiwan were valued and reconstructed. Wutai Township was subsidized from 2000 to cons truct the "new life of the Wutai tribe", and the main construction location was Slate Lane of Lin 10 in the Wutai tribe. In order to create unique "Rukai landscapes" and the image of a "s latetown", the local government inv ited a local national treas ure, the artist Mr. Pa-NanDu, as the designer, and local residents to visit other failed cases in Taiwan, in order to learn from the experience and develop the common consensus for "art street". In 2009, Typhoon Morakot severely struck southern Taiwan, including Wutai Township, and external roads and bridges were damaged. To avoid influencing the life of the indigenous people, the Directorate General of High way s constructed temporary culvert pipes, sidewalks, and steel bridges, in order that the indigenous people would not be trapped in the mountains. In October 2013, the Guchuan Bridge was opened, which is an external transportation line for Wutai (see Figure 3 and Figure 4). In addition, the roads to 
Sandimen were reconstructed. Since then, as their travel plans are not influenced by trans portation problem, visitors, touris m groups, and individual visitors can enter the tribe by various means of transportation (such as motorcycles and bikes ). Table 1 shows that after 2013, the number of vis itors to Wutai Township has grown constantly.

Table 1. Statis tics of the number of visitors to Wutai recreation area (2011-2019)

\begin{tabular}{|c|c|c|c|c|c|c|c|c|c|}
\hline Year & 2011 & 2012 & 2013 & 2014 & 2015 & 2016 & 2017 & 2018 & 2019 \\
\hline $\begin{array}{c}\text { Number } \\
\text { of } \\
\text { visitors }\end{array}$ & 22,652 & 31,679 & 75,991 & 135,849 & 188,952 & 215,587 & 225,147 & 218,624 & 222,343 \\
\hline
\end{tabular}

Source: statis tics of TourismBureau on number of visitors in Wutairecreation area

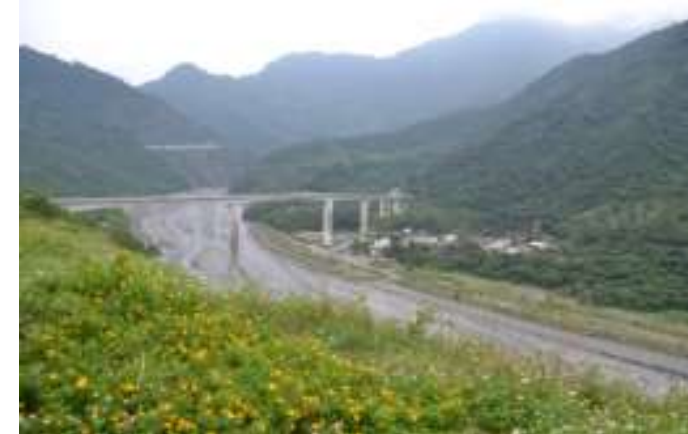

Figure 3. Guchuan Bridge

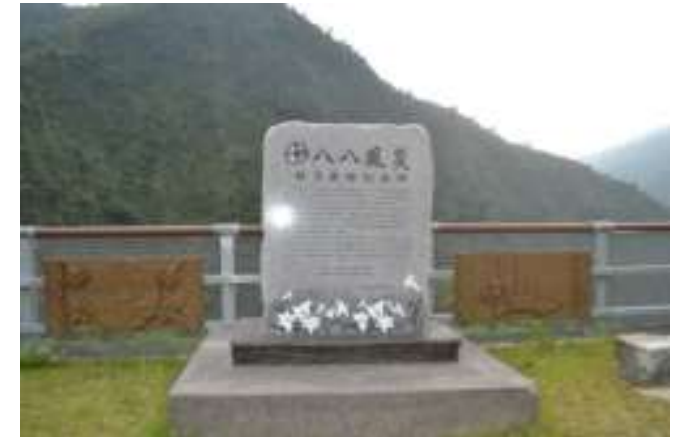

Figure 4. Monument of the heroes in Typhoon Morakot

\section{ANALYSIS OF TOURISM RESOURCES OF THE WUTAI TRIBE}

At present, the traditional culture of Rukai is still preserved by the Wutai tribe, such as costumes, ceremonies, art, architecture, socialclas s system, etc. There is a Rukai mus eumthat collects and exhibits the numerous traditional relics of Rukai and shows the various dimensions of the tribe. In the museum (see Figure 5), touris ts can approach the cultural origins and background of Rukai and learn the related knowledge. The museum is positioned as a permanent cultural preservation and national education institution, which reinforces local identification and the sense of belonging to the group, and continues the traditional culture of Rukai, thus, visitors can recognize the cultural background of Rukai. In addition, by in-depth visits in the Wutai tribe, people can discover the spirit of Rukai in local buildings (see Figure 6), street views, and humanity.

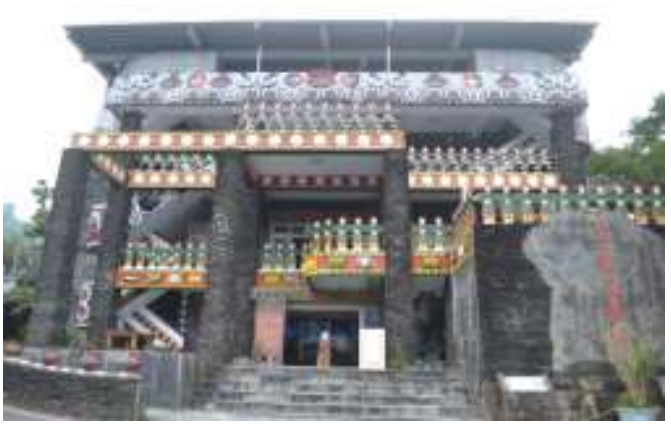

Figure 5. Rukai museum

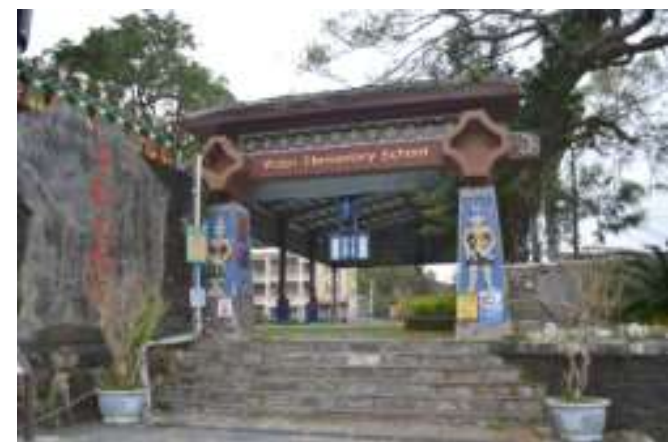

Figure 6. Wutai elementary school

According to the local people in the Wutai township office and Wutai tribe, more than $95 \%$ of residents in Wutai are Christians, and the local Chris tian church bring s mental peace. Over three vears, the residents of the Wutai tribe constructed a church using the traditional Rukai hou sing s tructure and special s late and s tone, and it has become one of clas sical works of important public art that can be seen around the village (see Figure 7). In addition, the house of the chief Dalabayang is preserved in the village, which has a yard around the house. For the indigenous people of the Wutai tribe, Dalabay ang is the authentic noble and chief. When the chief has to announce affairs important to the indigenous people, they would meet in front of the chief's house. 


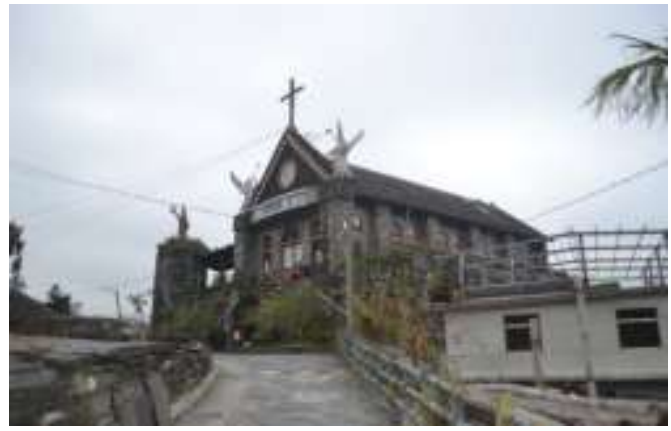

Figure 7. Christian Presbyterian Church

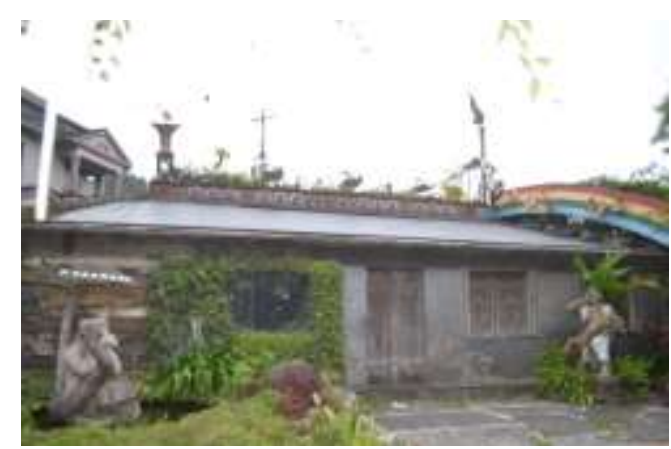

Figure 8. House of the chiefDalabayang

Slate Lane is located beside the zig-zag of slate houses on a hill of the Wutai tribe. When walking through Slate Lane, visitors can appreciate the beauty of Rukai buildings, thus, the lane is also called art street. The lane was constructed according to the residents' numerous discussions, and the "image design" of each house is based on the hierarchical symbols of this traditional society. The walls of public spaces show life as it was in the past, including hunting, cloth weaving, weaving, the treatments of shamans, ceremonies and legends, which are based on s late sculptures, cementreliefs, and large-s cale 3D cement statues. Slate Lane reveals the new landscape of Rukai culture around the tribe (see Figures 912). The researchers visited Slate Lane for several times and found that there were indigenous people selling handicrafts with Rukai characteris tics along the way. They also enthusiastically explained the characteristics of their ethnic groups and the development process of the tribe. They have als o heard from tourists and criticized by some scholars that the decoration of Slate Lane and Wutai tribe lacks the authenticity of indigenous culture. However, the Rukai people interviewed mentioned that in modern society, few indigenous people live in traditional houses. They als o try their best to highlight the cultural characteristics of the Rukai nationality in modern buildings, and even retain some tradit ional buildings so that the next generation can understand their cultural roots.

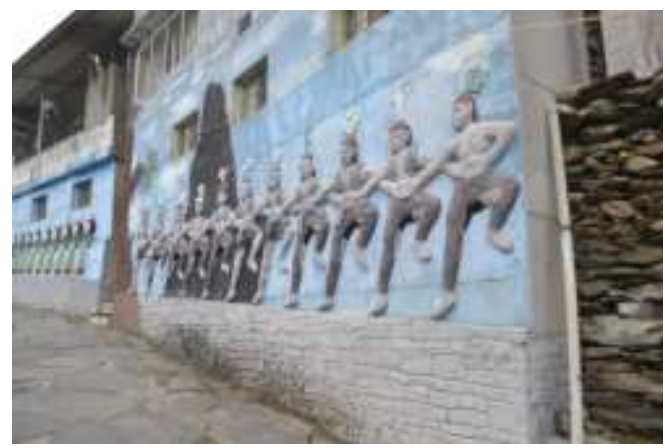

Figure 9. Rukai men's dance in the ceremony

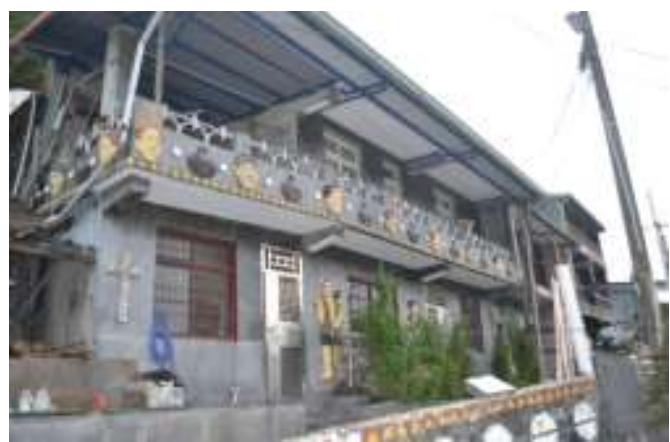

Figure 11. Cultural image of Rukai of Slate Lane

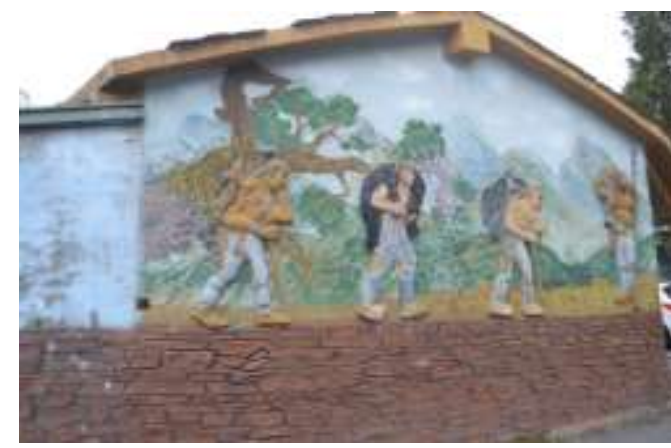

Figure 10. Rukai warriors carry the prey from the mountain

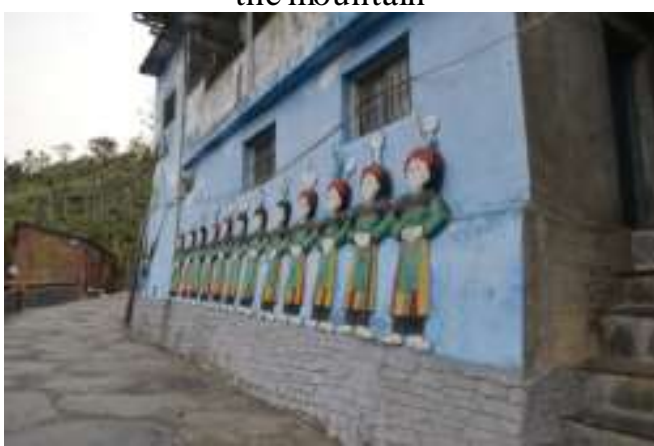

Figure 12. Rukaiwomen's dance in the ceremony

\section{DISCUSSION}

Gunn and Var [9] introduced the successful operational factors of tourism destinations. "Supply" includes attractions, promotions, transportation, information, and services. Regarding attractions, Wutai successfully creates an exotic culture to attract visitors. According to Smith's analysis, four factors related to indigenous peoples' tourism development are environment (habitat), anthropological tradition (legacy), cultural influence (his tory), an d handicrafts for sale [10,11]. Thus, when tourists vis it the Wutai tribe, they are most interested in the unique and spiritual connection with culture and land, the values associated with the culture, the religion, skills, and knowledge, and the his tory and ev olution of indigenous 
peoples' development. In addition, with long-term governmental control and its high altitude, the Wutai tribe conserves the primitive forest and environment. Some vis itors arrive to enjoy ecological tourismand mountain climbing, which are local attraction factors. The findings of this study are consistent with the previously mentioned key operation success factors for tribal tourismin Taiwan: indigenous culture [12,13] and natural res ources [14,15] are the main attractions for the visitors.

Regarding promotion, after the implementation of weekend holidays in Taiwan, in -depth tribal and ecological tounism became popular, and some TVnews and variety shows have been based on the Wutai tribe. Furthermore, in recent years, with the trend of international ecological tourism, the Wutai tribal area, which was previously considered to be an outdated and remote area, has become an important national site to promote "ecological culture tourism". Although the tourism development of the Wutai tribe is mostly implemented by the township office and private groups, such as community development and tourismdevelopment associations, the Wutai tribe is part of the available recreation in Wutai and in the neighboring areas, including the site of Sandimen of Shenshan tribe, which is part of the Maolin National Scenic Area. Touris m marketing relies on the assistance and promotion of governmental sectors, including the tourism department of Pingtung County government. Regarding transportation, as mentioned above, since typhoon Morakot, the Guchuan Bridge connects visitors with the tribe; in fact, the trip takes less than threehours. Regarding information, visitors can easily obtain the local situations and tourist res ources of the tribe on guesthouse web pages, the Wutai township office, Pingtung County Government, and Maolin National Scenic Area. Regarding services, grocery stores are available, gues thouses provide accommodations, and street vendors sell traditional indigenous food and BBQ. In the process of indigenous peoples' touris mdevelopment, the most critical is the support of local residents and their respect for the visitors [14,15].

Sometimes, when the visitors crowd into the area, they do not respect the lives of the localindigenous peoples, which results in some negative effects; however, with the promotion of tribal organizations and touris minformation, such negative situations are improved. In addition, the sale of indigenous people's handicrafts is important for the development of tribal touris $\mathrm{m}$, thus, some indigenous people sell traditional Rukai jewelry as souvenirs. From the above findings, the reasons for the success of Wutai tribe touris m development are similar to those of the Ts ou tribe in Alishan, Taiwan. The most important factor is the characteristics of indigenous culture, together with the ecological en vironment resources [16].

\subsection{Conclusion}

\section{CONCLUSION AND SUGGESTIONS}

According to the touris m development process of the Wutai tribe, the intent of development is to create economic opportunities, improve local living environments, and construct the unique characteristics of an indigenous tribe. In fact, since the government intends to take care of indigenous tribes in remote areas, the developments to date are associated with government policies. According to the analy tical results, the main attraction of tourismin the Wutai tribe is Rukai culture and natural res ources. Although the Wutai tribe is located in a remote area, the convenience of external transportation and acces sibility are the reas ons for the development of cultural and ecological tourismin the area. The Wutai tribe is lis ted as a model tribe and an important site of ecological and cultural touris m, thus, with the marketing of governmental sectors and tribal organizations, tourisminformation (web pages, promotion, and touris mfairs), and mas s media reports, the public learn about the tribe, and intend to vis it the village on holidays. Finally, the services in the tribe, including food, accommodation, tour guides, and the friendliness of the indigenous peoples, are the key factors for tribal tourism development.

\subsection{Suggestions}

In indigenous tribes, experiencing the indigenous peoples' cultural life is the key factor for vis itors, who mainly intend to appreciate the charming mountainou s landscapes. Thus, while focusing on hardware, local companies should conserve their primitive culture and natural resources, and avoid excessive exploitation. They should also design experiential activities according to localtraditional Rukai culture and reinforce touris t information for visitors, in order to avoid their negative impact on the tribe. In addition, for the tribes that intend to develop indigen ous touris $m$, they can check whether they have the conditions for development, including indigenous peoples culture, ecological landscape resources, hospitality and touris ms ervices, and friendly residents' attitude. In addition, the assistance of government departments is an essential factor for the success of tribal touris $m$. Therefore, it is necessary for the tribes to set up development association, receive the assistance of the government and professionals, and establish the tourism industry of the tribes, so as to promote the positive development of the tribal economy.

\section{ACKNOWLEDGEMENTS}

This study was supported by a grant from National Social Science Foundation of China (No.18BMZ130).

\section{REFERENCES}

[1]Hinch, T. and Butler, R. Indigenous tourism: A common ground for discussion. London: International Thomson Business Press, 1996.

[2] Pratt, S., Gibs on, D., and Movono, A. Tribaltouris min Fiji: An application and extension of smith's 4Hs of indigenous 
Tourism. Asia Pacific Journal of Touris mResearch, 2013; 18(8), 894-912.

[3] Taiwan Tourism Bureau. Tribal light travel - Southern Taiwan. September 27, 2020 Available: https://theme.taiwan.net.tw/tribe/south_introduction.html

[4] Maolin National Scenic Spot. Wutai Recreational Area. September 27, 2020 Available: https://www.maolinnsa.gov.tw/04000088.html

[5] Chen, Po-Han. Economic transition of Rukai Wutai. Unpublished master thesis, MBA program, School of management, Taiwan University of science and technology, 2020.

[6] Taiwan Council of Indigenous Peoples. 2019 Population statistics of Indigenous peoples in Taiwan. 2020; 8: 27. Available https://www.apc.gov.tw/portal/docDetail.html?CID=940F9579765AC6A0\&DID=2D9680BFECBE80B63BAF0DC1 D8B674CC

[7] Chen, Qilu. Family and marriage of the Rukai people in Wutai, Pingtung, Taiwan, Journal of China Nationalities, 1955; 1:103-123.

[8] Lai Qiyuan. The beauty and sadness of the Rukai nobles in Wutai tribe - A study of the power status changes of the Rukai nobles. Unpublished master thesis of National Development Institute of, National Dong Hua University, Hualian, Taiwan, 2008.

[9] Gunn, C. A., and Var, T. Touris mplanning: basics, concept, cases $\quad 4^{\text {th }}$ ed $)$. New York: Routledge, 2002.

[10] Smith, V. Indigenous tourism: The four Hs. In R.W. Butler and T.D. Hinch (eds.), Tourism and Indigenous Peoples (pp. 283-307). Toronto: International Thoms on Business Press, 1996.

[11] Kunas ekaran,P., Gill, S. S., Talib, A. T., and Redzuan, M. Culture as an indigenous tourismproduct of Mah Meri community in Malaysia. Life Science Journal, 2013; 10(3), 1600-1604.

[12] Huang, Hui-Chuan., Liu, Chia-Hao., and Chang, Hsiao-Ming. Does tourism development bring positive benefit to indigenous tribe? Case by Dongpu in Taiwan. Advances in Research, 2015; 4(4), 235-246.

[13] Chang, Hsiao-Ming., Hung, Chiu-Hui., and Chou, Chin-Lung. A study of Alishan indigenous tribal tourism development in Taiwan. Asian Journal of Environment \& Ecology, 2018; 8(1), 1-12.

[14] Chang, Hsiao-Ming and Chang Liao, Li-Chu. A Study of indigenous tribe tourismplanning and developing-Case by Huanshan in Taiwan. Journal of International Management Studies, 2014; 9(1), 146-155.

[15] Chang, Hsiao-Ming and Huang, Hui-Chuan. A study of indigenous tribe tourismplanning and developing-Case by Tamalung in Taiwan. Journal of International Management Studies, 2014; 9(2), 87-94.

[16] Chang, Hsiao-Ming., Hung, Chiu-Hui., and Chou, Chin-Lung. A study of Alishan indigenous tribal tourism development in Taiwan. Asian Journal of Environment \& Ecology, 2018; 8(1), 1-12. 